\title{
Determination of Appropriate Harvesting Age for Aloe vera Yield and Yield components at Wondo Genet, Southern Ethiopia
}

\author{
Dejene Tadesse Banjaw Tigist Germen Wolde \\ Ethiopian Institute of Agricultural Research, Wondo Genet Agricultural Research Center \\ *Corresponding Author: Dejene Tadesse Banjaw, P.O. box 198 Shashamane, Ethiopia
}

\begin{abstract}
Despite the fact that Aloe vera is an important medicinal plant in Ethiopia, an appropriate harvesting age is not known. This study was conducted to determine Aloe vera harvesting age for better yield and yield components. The experiment was arranged in a randomized complete block design (RCBD) design and consisted of three replications and five treatments $(12,14,16,18$ and 20 month after transplanting). Data were subjected to ANOVA using SAS computer software version 9.3 and differences between means were assessed at $5 \%$ probability level. Results of the experiments showed that all parameters were significantly affected by harvesting age treatments except jell weight. The highest significant plant height, leaf length, leaf width, leaf number per plant, leaf weight per plant, single leaf weight were obtained harvesting at 20 month after transplanting treatment while the lowest significant values were obtained from plots harvested at 12 month after transplanting. Even though statistically not significant, increase in harvesting from 12 month to 20 month after treatment, jell weight per leaf was increased by $30.18 \%$. Hence, weighting Aloe vera until 20 month after transplanting was recommended for higher yield and yield components for growers in same agro-ecologies with the study area. However, further scientifically sound agronomic studies should be carried out to broaden our understanding of the time of aloe vera harvesting age.
\end{abstract}

Keywords: Aloe, harvesting age, leaf yield

DOI: $10.7176 / \mathrm{JNSR} / 9-23-04$

Publication date: December $31^{\text {st }} 2019$

\section{INTRODUCTION}

Aloe is a succulent perennial tropical plant that belongs to Liliaceae family. More than 360 species reported in the world among which Aloe vera is known for its medicinal values (Hasanuzzaman et al, 2008). Aloe vera produced for its succulent, thick, triangular leaves that contain different chemical constituents having medicinal properties particularly for digestive system, wound, burn and skin problems (Hamman, 2008). Besides, Aloe vera products used for food, alcohol and beverage ingredients in addition to cosmetic and toiletry industries. Aloe vera growth, yield as well as gel and aloin content affected by harvesting age. Chemical constituents of a plant affected by management practices, environmental factors, plant species, part used and plant age (Pushpan et al, 2012). Studies indicated the importance of Aloe vera maturity time for its economic yield (Ahlawat et al, 2013). According to Hazrati et al. (2011), In Ethiopia, Aloe vera is one of the recognized medicinal plant and large number its products, such as soap, body lotion, hair oil and juice, are available in various places. However, despite the importance of Aloe vera in cosmetic, pharmaceutical and food industry is well understood, there is information gap on agronomic practices of the plant. In addition to health benefits, currently it has better socioeconomic values in the country. Wolde (2015) has reported as Aloe vera produced in different agro ecologies in Ethiopia. However, its plantation is small and restricted to few gardens because of limited information on production practices. Moreover, proper time of Aloe vera harvesting age is not known in the country and for a better production of the plant, appropriate information on production and handling practices should be identified and documented. Therefore, the objective of this experiment was to determine appropriate harvesting age of Aloe vera for higher economic yield and yield components.

\section{MATERIAL AND METHODS}

The experiment was conducted during 2014/2015 cropping season at Wondo Genet Agricultural Research Center (WGARC), which is geographically located at $7^{0} 19^{\circ}$ North, $38^{0} 38^{\circ}$ East and 1876 meter from sea level. The study area is has average annual rainfall of $1000 \mathrm{~mm}$ and average minimum and maximum average temperature of $12.02^{\circ} \mathrm{C}$ and $26.72^{\circ} \mathrm{c}$ respectively. The soil textural class of the study area is sandy clay loam with $\mathrm{pH}$ 6.4. Aloe vera suckers for seedling preparation was taken from WGARC botanical garden and field transplanting was done using uniform seedlings raised in polyethylene bags. The experiment was arranged in randomized complete block design in three replications. The treatments of the experiment include harvesting at 12,14, 16, 18 and 20 months after transplanting. The plot size was $2.5 \mathrm{mx} 2.5 \mathrm{~m}$ and the distance between plants in arrow as well as between two rows was $50 \mathrm{~cm}$. Five central plants, excluding the boarder plants, were selected for data collection in each experimental plots. Data on plant height, leaf length, leaf width, number of leaf per plant, leaf weight per plant, single leaf weight, and jell weight per leaf were recorded and subjected to analysis of variance using SAS computer software version 9.3. Whenever the ANOVA indicated the presence of significant variations between treatments, 
differences between means were assessed using least significant difference (LSD) at 5\% probability level to examine where the variations lay and it was indicated as LSD $(0.05)$ to indicate the minimum difference between mean values under comparison for the variation to be significant or not. The results of the analysis were combined and presented together under the results and discussion.

\section{RESULTS AND DISCUSSION \\ Plant Height (cm)}

Results of analysis of variance showed that plant height was significantly $(\mathrm{p}<0.05)$ affected by harvesting age treatments (Table1). The lower significant plant height $(46.67 \mathrm{~cm})$ was obtained from harvesting at 12 months after transplanting and the highest height $(57.81 \mathrm{~cm})$ from harvesting at 20 months after transplanting. Plant height increased with increasing harvesting age that might be due to more time to use available growth resources such as light, nutrients, and water at an extended growth period of the plant. This is similar with the findings of Gebremeskel and Woldetsadik (2015), who reported significant lower plant height at lower harvesting age of geranium.

\section{Leaf Length (cm)}

Analysis of variance showed that Aloe vera leaf length was significantly $(\mathrm{p}<0.01)$ affected by harvesting age treatments (Table1). Increase in harvesting age resulted in increased leaf length as the lowers significant value (42.95) was obtained at 12 months after transplanting (Table2).

\section{Leaf Width (cm)}

ANOVA resulted as Aloe vera leaf width was significantly $(\mathrm{p}<0.01)$ influenced by harvesting age (Table1). Delay in harvesting age resulted increase in leaf width. It seems that, as the plant gets more growing periods, width of leaf become wide that could be due to more resource utilization.

Table1: Analysis of variance for yield and yield components of Aloe vera as affected by harvesting age

\begin{tabular}{|c|c|c|c|c|c|c|c|c|}
\hline $\begin{array}{l}\text { Source of } \\
\text { variation }\end{array}$ & DF & PH & $\mathbf{L L}$ & $\mathbf{L W}$ & NLPP & LWPP & SLW & JWPL \\
\hline REP & 2 & 1.80 & 16.48 & 0.25 & 1.20 & 138722.66 & 6645.30 & 2106.67 \\
\hline TRT & 4 & $49.43 *$ & $63.57 * *$ & $2.90 * *$ & $9.39 * *$ & $4193567.70 * *$ & $42713.10 * *$ & $910.13^{\mathrm{ns}}$ \\
\hline ERROR & 8 & 11.25 & 3.90 & 0.20 & 2.64 & 1750093.01 & 2727.00 & 519.08 \\
\hline $\mathrm{CV}$ & & 6.30 & 4.00 & 6.16 & 9.70 & 9.16 & 14.40 & 15.40 \\
\hline
\end{tabular}

$\mathrm{NS}=$ not significant; $* * *$, and $* * *$ significant at $\mathrm{P} \leq 0.05, \mathrm{P} \leq 0.01$ and $\mathrm{P} \leq 0.001$ probability levels respectively; $\mathrm{REP}=$ Replication; $\mathrm{DF}=$ Degree of freedom; $\mathrm{PH}=\mathrm{Plant}$ height $(\mathrm{cm}) ; \mathrm{LL}=$ Leaf length $(\mathrm{cm}) ; \mathrm{LW}=$ Leaf width $(\mathrm{cm})$; $\mathrm{NLPP}=$ Number of leaf per plant (count); LWPP=Leaf weight per plant (g); SLW=Single leaf weight $(\mathrm{g})$; $\mathrm{JWPL}=\mathrm{Jell}$ weight per leaf $(\mathrm{g})$.

\section{Number of Leaf per Plant (count)}

Similar to that leaf length and leaf width, ANOVA showed as harvesting age exerted significant difference $(p<0.01)$ in number of leaf per plant (Table1). An increase in harvesting resulted in an increasing trend in number of leaf per plant (Table 2). This could be a good indicator of the importance of harvesting age for production of more leaf number per plant per unit area; hence, determination of appropriate harvesting age is crucial. As more number of leaf per plant obtained, there might be more chance to get more harvestable yield without affecting normal growth of the plant.

\section{Leaf Weight per Plant (g)}

ANOVA resulted as harvesting age significantly $(\mathrm{p}<0.01)$ affected weight of leaf per plant (Table1). Increase in harvesting age from 12 month to 20 month after transplanting resulted an increasing trend in leaf weight per plant (Table2). This could be due to increase in leaf length and leaf width at the higher harvesting age. Similarly, Kassahun et al. (2011) also reported an increase in peppermint leaf yield at higher harvesting ages indicating as plants have to be harvested at appropriate age for pre designed yield, quality and economic return.

\section{Single Leaf Weight (g)}

Similar to that of leaf weight per plant above, weight of single leaf was significantly $(\mathrm{p}<0.01)$ affected by harvesting age (Table1). Besides, the highest mean vale of single leaf weight was obtained at 20 month after transplanting (Table2). The higher weight of leaf at higher harvesting age could be possible sign for higher leaf weight per plant as well for determination of leaf yield per hectare.

\section{Jell Weight per Leaf (g)}

Unlike other parameters evaluated, jell weight per leaf was not affected $(\mathrm{P}>0.05)$ by harvesting age (Table1). Despite there were numerically equivalent, values of jell weight per leaf increased as harvesting age increased from 12 month to 20 month after transplanting (Table2). 
Table2: Mean performance of Aloe vera yield and yield components at different harvesting age

\begin{tabular}{llllllll}
\hline Treatments & PH & LL & LW & NLPP & LWPP & SLW & JWPL \\
\hline 12MAT & $47.67^{\mathrm{b}}$ & $42.95^{\mathrm{c}}$ & $5.77^{\mathrm{c}}$ & $13.93^{\mathrm{b}}$ & $3351.25^{\mathrm{c}}$ & $306.96^{\mathrm{bc}}$ & $137.35^{\mathrm{a}}$ \\
14MAT & $52.93^{\mathrm{ab}}$ & $49.25^{\mathrm{b}}$ & $6.97^{\mathrm{b}}$ & $16.53^{\mathrm{ab}}$ & $3973.80^{\mathrm{c}}$ & $293.83^{\mathrm{c}}$ & $138.31^{\mathrm{a}}$ \\
16MAT & $55.67^{\mathrm{a}}$ & $50.05^{\mathrm{b}}$ & $7.81 \mathrm{ab}$ & $16.60^{\mathrm{ab}}$ & $4007.20^{\mathrm{bc}}$ & $260.13^{\mathrm{c}}$ & $140.97^{\mathrm{a}}$ \\
18MAT & $56.73^{\mathrm{a}}$ & $51.91^{\mathrm{ab}}$ & $8.14^{\mathrm{a}}$ & $17.53^{\mathrm{a}}$ & $4781.50^{\mathrm{b}}$ & $395.34^{\mathrm{b}}$ & $145.20^{\mathrm{a}}$ \\
20MAT & $57.81^{\mathrm{a}}$ & $55.56^{\mathrm{a}}$ & $7.99^{\mathrm{a}}$ & $18.73^{\mathrm{a}}$ & $6528.70^{\mathrm{a}}$ & $556.39^{\mathrm{a}}$ & $178.81^{\mathrm{a}}$ \\
\hline LSD & 6.4 & 3.72 & 0.85 & 3.06 & 787.85 & 98.32 & $\mathrm{NS}$ \\
CV & 6.30 & 4.00 & 6.16 & 9.70 & 9.16 & 14.40 & 15.40 \\
\hline
\end{tabular}

$\mathrm{NS}=$ not significant; $\mathrm{CV}=$ Coefficient of variance; $L S D=$ Least significant difference; $\mathrm{PH}=\mathrm{Plant}$ height $(\mathrm{cm})$; $\mathrm{LL}=$ Leaf length $(\mathrm{cm})$; LW=Leaf width $(\mathrm{cm})$; NLPP=Number of leaf per plant (count); LWPP=Leaf weight per plant (g); SLW=Single leaf weight (g); JWPL=Jell weight per leaf (g). MAT=Months after transplanting; Means followed by the same letters with in a column for a given treatment are not significantly different at $\mathrm{p} \leq 5 \%$ level of significant.

\section{SUMMARY AND CONCLUSION}

Determination of harvesting age for perennial plants is one of the important agronomic practices for better economic yield. Appropriate plant harvesting age encouraged for yield, quality and economic returns. Aloe vera is important medicinal plant in Ethiopia and the current study was done to determine its appropriate harvesting age at Wondo Genet Agricultural Research Center. Leaf length, leaf width, plant height, number of leaf per plant, leaf weight per plant, single leaf weight significantly influenced by harvesting age treatments. Increase in harvesting age from 12 month to 20 month after transplanting significantly showed increasing trend except jell weight, which did not affected at all but numerically increased in similar manner. Hence, based on the current study, we recommend harvesting age at 20 month after transplanting for higher leaf yield and jell weight per area. However, further studies with respect to plant spacing, nutrient and water utilization should be conducted to broaden information on aloe vera production.

\section{REFERENCE}

Ahlawat KS., Sushil, Gulia S., Khatikar BS.2013. Effect of plant maturity on leaf growth, yield and physicochemical properties of aloe vera gel. Agro food industry HiTech.24 (1):35-37.

Gebremeskel H. and Woldetsadik K. 2015. Effect of plant spacing and harvesting age on growth, biomass and oil yield of rose-scented geranium. Basic research journal of agricultural science and review. 4(3): 94-101.

Hamman JH.2008.Composition and Application of Aloe vera Leaf Gel. Molecules.13:1599-1616.

Hasanuzzaman M., Ahmed K.U., Khalequzzaman KM., Shamsuzzaman AMM., Nahr K. 2008. Plant characteristics, growth and leaf yield of Aloe Vera as affected by organic manure in pot culture. Aust. J. Crop Science. 2(3):158-163.

Hazrati S., Sarvetani ST., Ramezani S. 2011. Effect of different harvest dates on growth characteristics and aloin content of Aloe vera. Advance in Environmental Biology.5(2): 439-442.

Kassahun BM., da Silva JT., Mekonnen SA. 2011. Agronomic characters, leaf and essential oil yield of peppermint as influenced by harvesting age and row spacing. Medicinal and Aromatic Plant Science and Biotechnology. 5(1): 49-53.

Pushpan R., Kumari H., Nishteswar K. 2012. Influence of Harvesting and Processing on Active Principles of Medicinal Plants. International Journal of Pharmaceutical and Biological Atchives. 3(6): 1283-1286.

Wolde GT. 2015. Evaluation of the performances of Aloe vera under different location in Ethiopia. International Journal of Science: Basic and Applied Research. 24(1): 51-57. 